\title{
Practice of Unconventional Gas Development and Engineer- ing Management Innovation in China
}

\begin{abstract}
This article analyses the recent progressive increase in resource quantity and production quantity of unconventional natural gas in China, describes its natural properties and the concepts, strategies and approaches of its development, summarizes the special techniques, management concepts and development modes formed in the process of its development, and puts forward proposals to accelerate the development of unconventional natural gas of China. The technically recoverable reserve of unconventional natural gas is 1.7 times that of conventional natural gas and its output in 2012 accounted for $41.8 \%$ of the total output in China. Chinese tight gas development has gained success, coal-bed methane development and shale gas production pilots have made important progresses. As the key feature of unconventional natural gas is "low grade", for the effective scale development, developers must build up the engineering concept of low-grade resources development, adhere to the low cost strategy, take the development route of "a step backward and then a step forward", apply such ideas and methods of engineering management as low cost dualistic integrative innovation, full control network management, economic limit theory, integrated operation and "four orientations" engineering management, establish a "two lows" engineering management system, and take reference of the successful development mode of the tight gas in Sulige and the coal-bed methane in the Qinshui ba$\sin$. In order to achieve the objective of rapid development of nonconventional natural gas in China and to accelerate the development pace, the government should continue to
\end{abstract}

Manuscript received December 10, 2013; accepted March 1, 2014

Wen-rui $\mathrm{Hu}$

CNPC Advisory Centre, Beijing 100724, China

Jing-wei Bao (凶)

Petro China Research Institute of Petroleum Exploration \& Development, Beijing 100083, China

Email: baojingwei@petrochina.com.cn

$\mathrm{Bin} \mathrm{Hu}$

College of Petroleum Engineering, China University of Petroleum, Beijing 102249, China;

CNPC Planning Department, Beijing 100007, China increase support, to speed up the reform of natural gas price adjustment, to set up national comprehensive development and utilization demonstration areas, to input in sustainable technological research and to promote engineering management innovation.

Keywords: natural gas, unconventional, tight gas, coal-bed methane, shale gas, engineering management, innovation, proposals

\section{Preface}

The twenty-first century is the century of natural gas. As a green, low-carbon, clean fuel and important chemical raw material, natural gas plays an increasingly important role in the world energy. Frequent environmental events and smog invasions all over the country in recent years brought the Chinese society to a general consensus about the need for a larger proportion of natural gas in primary energy, and for a vigorous development and utilization of natural gas. In addition to conventional natural gas resources (mainly sandstone gas and carbonate gas), the development and utilization of unconventional natural gas becomes more and more important. During the past ten years, tight gas and shale gas production in the United States grew rapidly, which caused a global revolution of unconventional natural gas and exerted significant influences upon the energy supply and economic development of the world.

By the term unconventional natural gas resources, the authors refer to the natural gas resources which are not yet fully understood and not yet fully developed with mature technology and experience. They mainly include: tight gas, coal-bed methane, shale gas, gas hydrate, gas dissolved in water, inorganic gas, basin centered gas, shallow layer biogenic gas, etc (Hu, 2010). Among these resources, tight gas, coal-bed methane, shale gas and gas hydrate have enormous potential, and developers have made much study of them, or are already well prepared to development them.

China has large proved reserves of unconventional natural gas and huge potential for its development. Developers 
have striven for significant advancement. They have realized large-scale development of tight gas (mainly tight sandstone gas), achieved important progress on coal-bed methane development, initiated shale gas development, and begun laboratory research on natural gas hydrate. In general, of unconventional natural gas development, China has accumulated considerable experiences in technology and management, which laid a good foundation for future development and utilization of unconventional natural gas resources. There are still some challenges. Therefore, it is of great significance for effective development, utilization and for further national energy security to review development techniques and management experiences concerning unconventional natural gas especially tight gas and coal-bed methane, analyze problems which the developers face with, and raise proposals to accelerate development and utilization.

\section{Progresses in unconventional natural gas development}

During the past 10 years, substantive progresses have been made in the development of unconventional natural gas in China, among which the most successful one is the tight gas development, followed by the development of coal-bed methane, and combustible ice sampling research has also made progresses. The development of shale gas has made positive progress, but has not yet reached the expectation, and there are emerging comments on the areas of resources, technology and management.

\subsection{Unconventional gas resources}

China has great potential in unconventional natural gas resources, the amount of resources of tight gas, coal-bed methane, shale gas and gas hydrate are about $401.2 \times 10^{12} \mathrm{~m}^{3}$, with technically recoverable resources $34 \times 10^{12} \mathrm{~m}^{3}$, which is 7.2 times, 1.7 times that of conventional natural gas respectively. With the progress of exploration and development technology and prove of the gas hydrate resources, the recoverable resources of unconventional natural gas in China will increase greatly.

\subsection{Production}

Chinese unconventional natural gas production reached $445.6 \times 10^{8} \mathrm{~m}^{3}$, which accounts for $41.8 \%$ of the total national natural gas output of $1,067 \times 10^{8} \mathrm{~m}^{3}$ in 2012 ( Hu, 2013A) (see Table 2).

Tight gas development in China has achieved great success, there has been a large-scale development in the Erdos Basin and the Sichuan Basin, the output reached $320 \times 10^{8} \mathrm{~m}^{3}$ in 2012 and increased by $64 \times 10^{8} \mathrm{~m}^{3}$, which has grown by $25 \%$ over 2011 (Hu, 2009A). Represented by Sulige large gas field, the tight gas development technology system in China, development engineering management tends to be mature, production scale ranks second in the world after the United States. Tight gas development has entered the period of rapid development, becoming the pioneer and leader of unconventional natural gas development.

Chinese coal-bed methane development has achieved significant progress, and has realized scale commercial development in the south of the Qinshui Basin, the eastern margin of the Erdos Basin in Inner Mongolia and Hancheng in Shaanxi. The output reached $125.1 \times 10^{8} \mathrm{~m}^{3}$ in 2012 and increased by $10 \times 10^{8} \mathrm{~m}^{3}$, which has grown by $8.7 \%$ over 2011 .

Chinese coal-seam experienced strong reformation with deep buried depth and higher coal maturity, the development of coal bed methane is quite difficult. Thus, the ground drainage coal-bed methane production scale is still small. After more than ten years of continuous development, coal-bed methane development research has made important achievements, but the breakthrough of core technology that adapt to the coal seam geological feature of China has not yet fully achieved. The average single well production is not high and the economic benefits are not obvious at the moment. With technological breakthrough and management innovation, it is believed that the period of great development of China's coal-bed methane will come soon.

Chinese shale gas production has achieved positive progresses, and had fulfilled the zero production breakthrough by 2012, which shows that shale gas development in China entered the pilot production stage. The shale gas pilot areas mainly concentrated in the Sichuan Basin currently. The Chinese government puts great attention to the development

Table 1 Chinese Unconventional Natural Gas Resources

\begin{tabular}{lcccc}
\hline & Tight gas & Coalbed methane & Shale gas & Gas hydrate \\
\hline Geological resources $\left(\times 10^{8} \mathrm{~m}^{3}\right)$ & $20 \sim 28$ & 36.8 & 134.4 & 206 \\
Technically recoverable resources $\left(\times 10^{8} \mathrm{~m}^{3}\right)$ & 11 & 12 & 11 & Not Proved \\
\hline
\end{tabular}

Note. Adapted from Zhao (2012), Zou, et al. (2013), and Qiu \& Deng (2012).

Table 2 Chinese Unconventional Natural Gas Production in 2012

\begin{tabular}{lccccc}
\hline Type & Tight gas & Coalbed methane* & Shale gas & Gas hydrate & Total \\
\hline Production $\left(\times 10^{8} \mathrm{~m}^{3}\right)$ & 320 & 125.1 & 0.5 & 0 & 445.6 \\
\hline
\end{tabular}

Note. Coal-bed methane production included surface production of $25.7 \times 10^{8} \mathrm{~m}^{3}$ and under coal mine production of $99.4 \times 10^{8} \mathrm{~m}^{3}$. 
of shale gas, introduced a number of measures to support it, and established Changning-Weiyuan national shale gas demonstration zone and Yan'an national continental shale gas demonstration zone, which all played positive role in promoting the development of shale gas.

Chinese gas hydrate has been made a lot of sampling and research work, and is still in the stage of research without any production pilot currently, which need a longer period of time to study and test before commercial development.

\section{The main knowledge and technology of unconventional natural gas development}

\subsection{Formed four basic understanding}

\subsubsection{The essential feature of unconventional natural gas}

Compared with that of conventional natural gas resources, the essential feature of unconventional natural gas is "low grade", that is, the resources are of poor and marginal resources. The feature shows itself in four aspects: (1) reservoir properties are poor, and formation permeability is relatively low; (2) resource abundance is comparatively low; (3) low single well production is low; (4) the economic benefit of development is poor even zero. Compared to the Kela- 2 and $\mathrm{Pu}-$ guang conventional gas fields, the Sulige Gas Field has low average porosity, average permeability, resource abundance and single well production rate, as demonstrated in Table 3.

\subsubsection{Unconventional natural gas development philosophy}

The characteristics of unconventional natural gas resources determines that the developer of this kind of resources must establish the concept of "low grade resource development engineering", that is, they must adhere to the conviction of "simplicity, low cost and new technology application", "attention paid to the actual effect", "many a little make a mickle, weight not refuse" in the whole process of development (Hu, 2013B). "Simplicity" here refers to the minimal and most essential development plan of low single well gas production and largely the amount of development investment for unconventional natural gas. "Low cost" refers to saving every dollar in each investment for the process of exploration and development. "New technology application" doesn't mean to apply the best new technology, but rather to useful and practical ones. The former is the technology to be marketable, the latter not refers to pursue showy but cost-effective. "Pay all attention to the actual effect" refers to ad- here to a pragmatic scientific attitude but not new technology and increasing production in the whole process of exploration and development. "Many a little make a mickle, weight not refuse" means every cubic meter of gas output must be cherished, collected, used, as far as possible to improve the commercialization rate without any waste because of the low single well production for unconventional natural gas. With the time and the number of producing wells increased, it is possible to form a considerable scale.

\subsubsection{Development strategy of unconventional natural gas}

Because of the low single well production of Chinese unconventional natural gas and low economic benefit, it is naturally have to take the low cost development strategy. The aim of low cost is to maximize economic benefit, which is a compromise at the conditions of low single well production with very difficult to improve the single well production greatly. Low cost development strategy means to invest as low as possible in the whole process of system designing, construction and management in order to decrease investment and increase economic benefit.

Adhere to the low cost strategy needs to pay attention to two points: firstly, it is not a contradiction between low investment and applying advanced technology even using cutting-edge technology. Cost saving is not the blind pursuit of indigenous methods to make do with whatever is available. It is to use suitable, practical advanced technology to get maximization development benefit. Take the Sulige Gas Field development as an example, a lot of high technology was applied in many aspects. Using large computer to build geological model for determining enriched blocks and well location; taking digital geophone readings to collect developing seismic waves and supplying multiple development plans for choosing with the help of computer simulation and etc. Packer is used for separate layer fracturing, downhole throttling devices, the wellhead high pressure emergency shut-off valve. The intelligent vortex precession flowmeter is used for measuring liquid and gas at the same time are all advanced technology products. Especially the well head remote controlling system, it is the very demand in the middle and late development stage of large, low permeability sandstone lithological gas field. The base control room can completely control and continuously adjust thousands of producing wells' working condition, and manage the intermittent producing wells conveniently and safely, which have saves a lot of manpower and material resources (Hu,2009B). Secondly, Low cost does not mean to take all measurement to reduce costs, but to apply moderately low cost strategy in the whole

Table 3 Comparison of Sulige with Typical Domestic Conventional Natural Gas Fields

\begin{tabular}{lcccc}
\hline Field name & Average porosity $(\%)$ & Average permeability $\left(10^{-3} \mathrm{~m}^{2}\right)$ & Abundance of reserves $\left(\times 10^{8} \mathrm{~m}^{3} / \mathrm{km}^{2}\right)$ & Single well production $\left(\times 10^{4} \mathrm{~m}^{3} / \mathrm{d}\right)$ \\
\hline Kela 2 Gas Field & $10.9-15.6$ & $0.78-49.4$ & 59.1 & $90-400$ \\
Puguang Gas Field & $8.17-12.0$ & $6.0-479.3$ & 55.06 & $>50$ \\
Sulige Gas Field & $4-10$ & 0.5 & $1.1-1.4$ & $1.0-3.1$ \\
\hline
\end{tabular}


development process. As in the stage of exploration and field pilot, high quality equipment and materials should be applied in order to ensure the test result, while it can reduce cost when technology matured.

\subsubsection{Development route of unconventional natural gas}

According to the development practice of the Erdos Basin's unconventional natural gas resources, combined with the experiences of American unconventional natural gas development, Chinese unconventional natural gas development route should firstly step backward and then go ahead. That means make the conventional techniques excellently and very fine to adapt to the characteristics of the reservoir in the initial development stage; When the production reaches a certain scale, with base of clear understanding of geological characteristics, it is the time to organize high-tech research to improve the technical level and enhance production further, and then adhere to scale development, centralize construction to decrease cost and realize economic development on a large scale ( $\mathrm{Hu}, 2013 \mathrm{~B})$. It is not a wise choice of using the new advanced technology at the beginning of research but can be used as experimental exploring in a small scale.

3.2 Formed primarily six featured technology for developing unconventional natural gas

Chinese tight gas development technology has matured and reached the advanced international level, partial coal-bed methane development technology tends to mature, shale gas development technology is in the exploring stage and the gas hydrate is still in the research stage. Thus, the featured Chinese unconventional natural gas development technology is mainly refers to tight gas development technology.

\subsubsection{Seismic acquisition and enrichment area prediction} technology

According to features of tight reservoir, the digital seismic acquisition core technology with the characteristics of "small group interval, large offset, high cover and digital geophone" was explored. And the obtained data have wider frequency band, better fidelity and improved quality com- pared with conventional seismic data. By using quantitative reservoir description technology based on three dimensional probability field, combined with the pre stack AVO attribute analysis, prestack elastic impedance and parameter inversion and drilling information, researchers can built 3D geological modeling based on reservoir distribution probability to improve the prediction accuracy of reservoir space. With the help of visualization technology, sand body space form and the effective reservoir distribution can be described in detail. With the application of this technology, the gas layer drilling ratio of well XH1 reached to $78.04 \%$ and its gas testing open flow capacity was $1,525,000 \mathrm{~m}^{3} / \mathrm{day}$; and the gas layer drilling ratio of well $\mathrm{YH} 2$ reached to $67.45 \%$ and its gas testing open flow capacity was $1,150,000 \mathrm{~m}^{3} / \mathrm{day}(\mathrm{Lu}, 2013)$.

\subsubsection{Horizontal well drilling technology}

Horizontal well has the advantages of maximum reservoir contact with higher producing degree of reserves and single well production, saving land, and has become a key technology to the exploration and development of unconventional natural gas resources compared with the conventional vertical well. With the progress of technology and development practice of unconventional oil and gas, many kinds of new horizontal wells have been developed in these years. Such as high angle deviated horizontal well, sidetracking horizontal well, multi-lateral horizontal wells, pinnate horizontal wells, cluster wells, under-balanced horizontal wells, and the horizontal well drilling records have been refreshed constantly in China. As of April 2013, the longest horizontal well in China is Gaoping-1 with horizontal length of 3462.1 meters and the deepest Horizontal well is Yuanbar $121 \mathrm{H}$ with vertical depth of 6991.19 meters. While the horizontal well with most branches is the Jing 52-H1Z, which has 20 fishbone branches and the main horizontal length is 1,000 meters with 180 meters length of the branches on average and its total effective footage is 4,567 meters in production layers (Wu, 2013).

\subsubsection{Staged fracturing technology}

Staged fracturing technology is a core technology in the development of unconventional oil and gas resources, and hor-

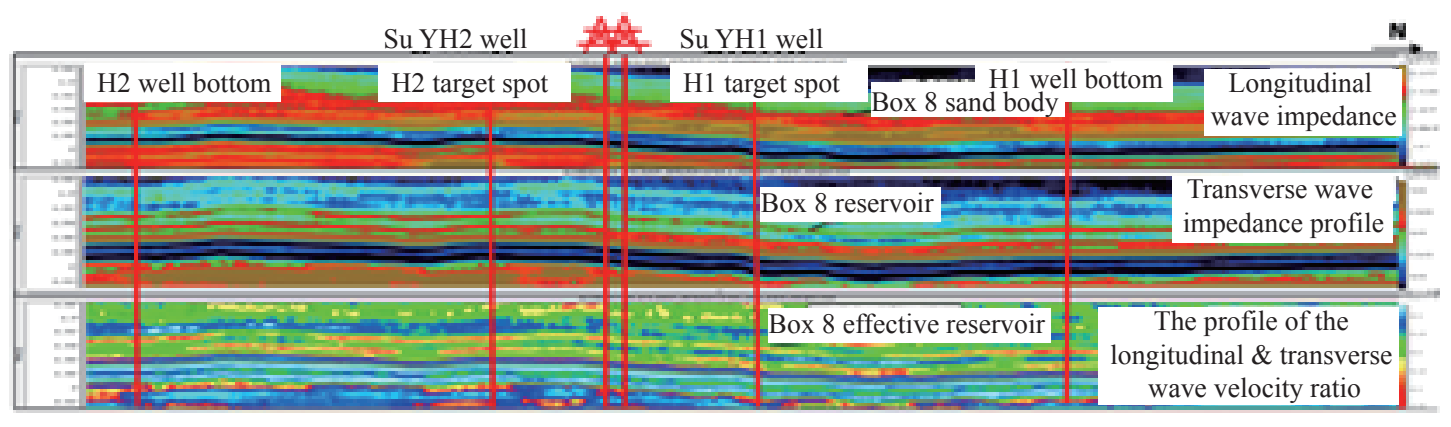

Figure 1. Prestack inversion prediction profile of XH1 and YH2 horizontal well. 
izontal wells plus staged fracturing are the key for effectively development of low-grade unconventional gas resources. Fracturing technology was firstly implemented in a well in Yumen Oil Field (Well N-1 in Laojunmiao reservoir) in 1955 in China. After nearly 60 years' development, Fracturing technology has experienced plugging remove fracturing, single well fracturing, integral fracturing, development fracturing, vertical multi-layer fracturing and horizontal well multistage fracturing. Great progress has been made in fracturing technology in China, and formed 6 types of staged fracturing technology (Wu, 2013): (1) Horizontal well double seal card single staged fracturing technology, the largest fracturing stage is 15 for well Zhoufu 51-Ping 52; (2) Casing slip packer staged fracturing technology, the largest fracturing stage is 15 for well Hei-H-Ping 2 in Jilin Oil Field; (3) Horizontal well hydraulic sandblasting staged fracturing technique, the largest stage is 21 for well Yang Ping 10 in the Changqing Oil Field ; (4) Open-hole packer slip staged fracturing technology, the largest stage is 21 for well DBG-Ping 2 in Jilin oilfield; (5) Fast drilling bridge plug plus cluster perforation fracturing technology, the largest fracturing stage is 10 for Yue10178-H1; (6) Pitching casing sleeve technology, five wells have been tested and layers which used multiple fracturing upper to 5 layers at one time. The horizontal well of Ning 201-H1 that produced shale gas used fast drilling bridge plug plus cluster perforation fracturing technology got test production of $13 \times 10^{4} \mathrm{~m}^{3} / \mathrm{d}$ in Southwest Oil and Gas Field of Petro China. It has $1045 \mathrm{~m}$ of horizontal section length and 10 section of staged fracturing with injected liquid $21,610 \mathrm{~m}^{3}$, supporting agent $568 \mathrm{~m}^{3}$ (see Figure 2).

\subsubsection{Downhole throttling technique for gas production}

Downhole throttling refers to putting a throttling device into lower wellbore to realize restricting flow and reduce pressure decrease in gas wells. This technology has follow advantages: (1) Prevent forming hydrate and increase the time ratio of production; (2) Greatly reduce the ground pipeline operating pressure (see Figure 3), optimize and simplify the surface flow, reduce the cost of construction and operation; (3) Be helpful for preventing the layer excitation and inter well interference, realization stable production and controlling pressure. On the Bases of downhole throttling, gas field formed low pressure gas gathering process technology with the core part is "wellhead without heating, no alcohol injection, measuring with liquid, inter well connected, normal temperature separation, two stage turbocharging and centralized processing". After application this technology and process, single well production rate increased by $20 \%$, ground construction investment fell by $36.7 \%$, well opening rate increased from $67 \%$ to $97.2 \%$ in Sulige Gas Field. Thus, this technology becomes the core technology of gas field development in the Erdos Basin (Hu, 2009A).

3.2.5 Drilling and completion technology of pinnate horizontal well for coal-bed methane

Coal-bed methane pinnate horizontal well technology is formed through introduction, absorption and innovation, which is an advanced technology with completely independent intellectual property rights for coal-bed methane devel-

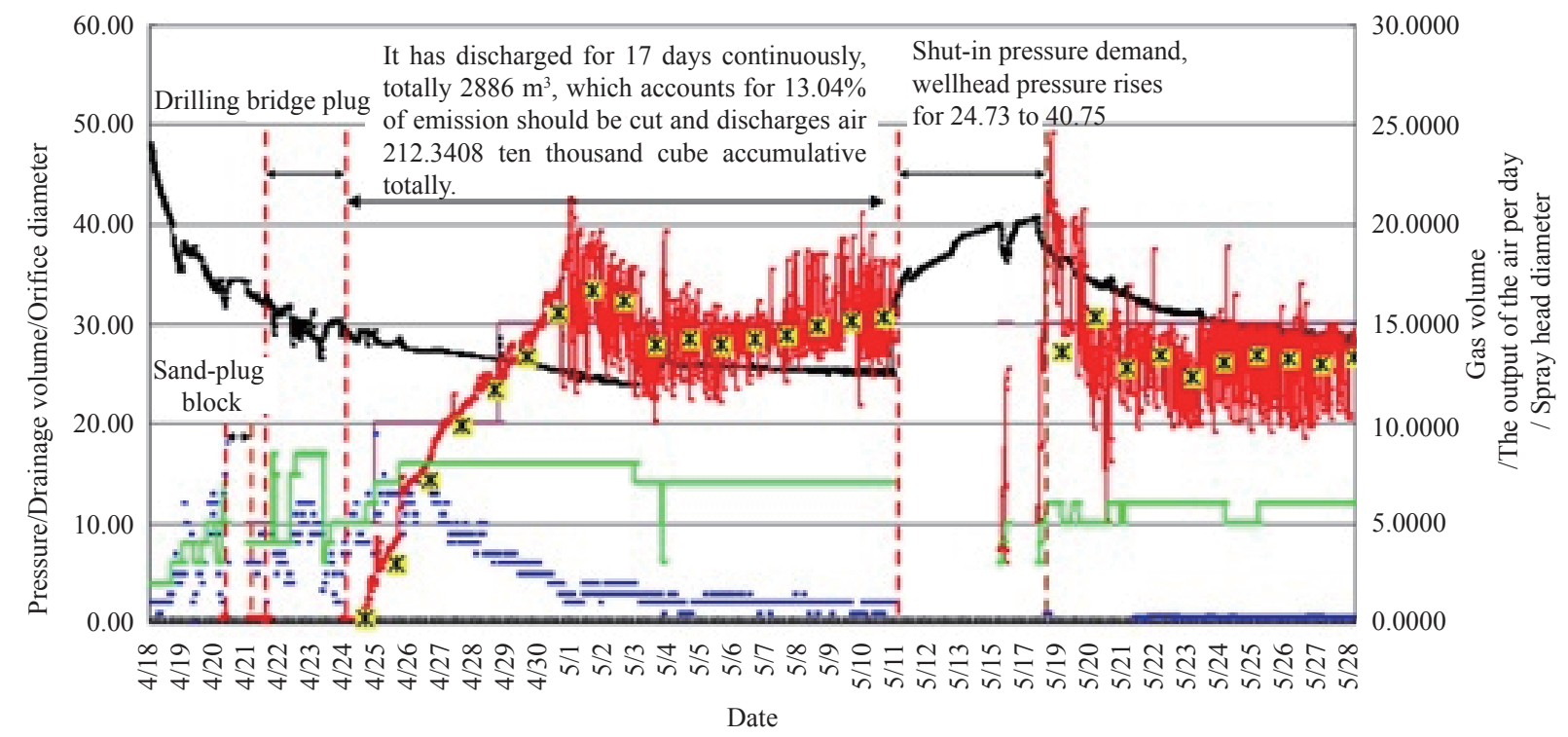




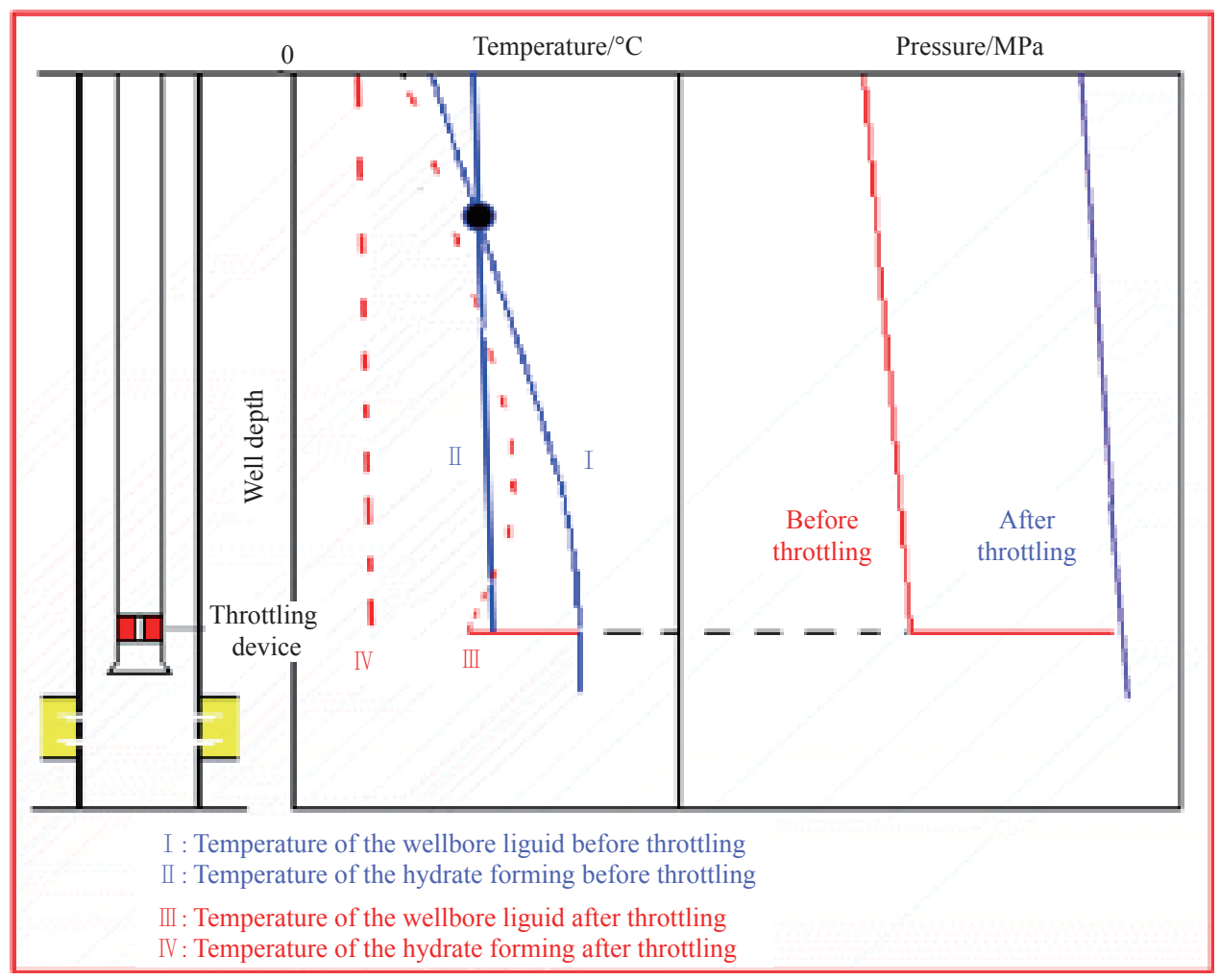

Figure 3. Temperature, pressure profile around wellbore before and after downhole throttling.

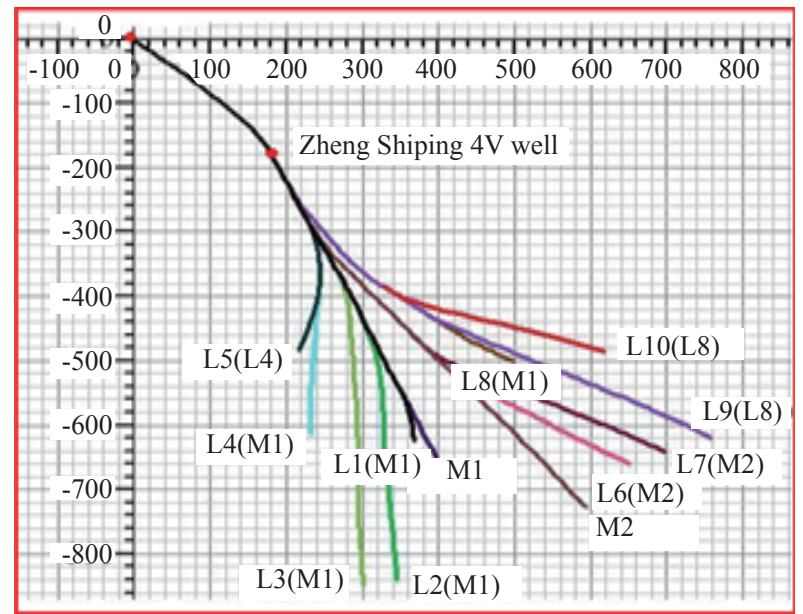

Figure 4. Horizontal projection of well Zheng Shiping 4H.

opment (see Figure 4). It has the advantages of enhancing conductivity, reducing reservoir damage, increasing single well production and is suitable for coal formation's steep slope belt with high permeability. After years of technology research, five internationally advanced technologies have developed; there are well trajectory design and optimization technology, aerated UBD technology, high performance composite cavitation technology, communication technology and formation identification technology. Four key devices have been devel- oped, such as balance charging equipment, composite burrow tools, communicating and positioning equipment and comprehensive identification formation instrument. With the help of technology progress, drilling cycle shortened by $41.4 \%$, coal seam drilling ratio increased to $94.7 \%$, the drilling cost reduced by 23.1\% (Zhou, 2013). The Southern part of the Qinshui Basin has completed more than 60 coal-bed methane pinnate horizontal wells with single well gas production between 1.5 to $6.0 \times 10^{4} \mathrm{~m}^{3} / \mathrm{d}$, which is a very good development results (Chen, Yang, Wang, Chen \& Wang, 2010).

\subsubsection{Micro-seismic fracture monitoring and evaluation} technology

Micro-seismic fracture monitoring technology mainly refers to monitor crack activities and fluid flow in the oil and gas production layer during the process of fracturing oil and gas reservoir which induced low intensity micro-earthquake phenomenon similar to a natural earthquake. It can help to optimize the management of oil and gas reservoir and provide technical basis for making decisions in the process of exploration and development of tight reservoirs. Generally speaking, it can provide real-time information of fracture height, length, azimuth angle, geometry and spatial distribution, to optimize the develop measures such as fracturing design and optimization of well pattern to enhance recovery factor. The effect of fracturing operation is closely related to increasing production, enhancing recovery factor and effec- 


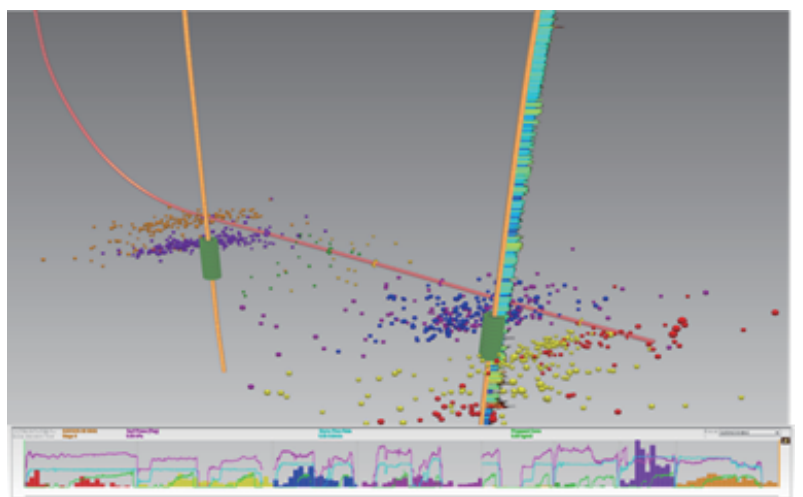

Figure 5. Micro-seismic fracture monitoring results of well Sudong $55-66 \mathrm{H} 2$.

tively developing reserves, while micro-seismic monitoring technology is an effective means for real time monitoring the fracturing effect. By Application of micro-seismic fracture monitoring technique, the fracture of well Sudong 55$66 \mathrm{H} 2$ has 235 to 560 meters of half-length, 42 to 79 meters of height and 100 to 220 meters of bandwidth. It showed that fractures break through the choke zone transversely and interlayer vertically, formed a complex fracture network and its fracturing volume increased by more than 2 times compared with the conventional fracturing (Lu, 2013).

\section{Engineering management achievements of unconventional gas development}

4.1 Exploring and summarizing a variety of engineering management methods

\subsubsection{Low cost dual integrations innovation}

Low cost dual integrations innovation is a summary of the successful practice of developing the Erdos Basins' unconventional oil and gas in China, which was formed by 8 years of research in the Ansai Oil Field, matured through 7 years' research in the Sulige Gas Field. Low cost dual integrations innovation refers to applying of system engineering theory and combining with technological and management innovation to decrease cost and increase production through integrating manpower, organization, investment to get considerable economic benefits in the development of unconventional oil and gas field (see Figure 6). "Dual" refers to technology and management. It emerges management theory into technology research, to improve exploration and development efficiency and reduce the cost of production oil and gas through the management innovation, which changes the past single technology research development model. That fully respects the objective development law of unconventional oil and gas resources, and realizes scale and effective development of unconventional oil and gas fields that are difficult to develop and explores a new method to solve major projects' technical problems (Hu \& Zhai, 2010). Taking the low cost dual integrations innovation as a guide, there are representative achievement: (1) Guided the development of Sulige tight gas field, built the highest production gas field in China at present; (2) Guided the technology research in Ansai low permeability oilfield, built the first large-scale extra low permeability oil field in China; (3) Created the famous "Sulige Gas Field development mode" and "Ansai Oil Field development mode"; (4) After technology innovation and development, guide the rapid oil and gas production growth of Changqing Oil Field of Petro China. By the end of 2013, the field's oil and gas annual production is equivalent to $5,195 \times 10^{4} \mathrm{t}$ of crude oil, built the "western Daqing" (A basin's oil and gas annual production equivalent to $5,000 \times 10^{4} \mathrm{t}$ of crude oil) and became the largest oil and gas field in China.

\subsubsection{The theory of full control network management}

The core part of the full control network management theory (Hu, 1991) is that successful managers would rather administrate by enterprise than completely control it. In general, it is to classify the key point, second key point and general point by management organization network to organize the development production and the process construction.This meth-

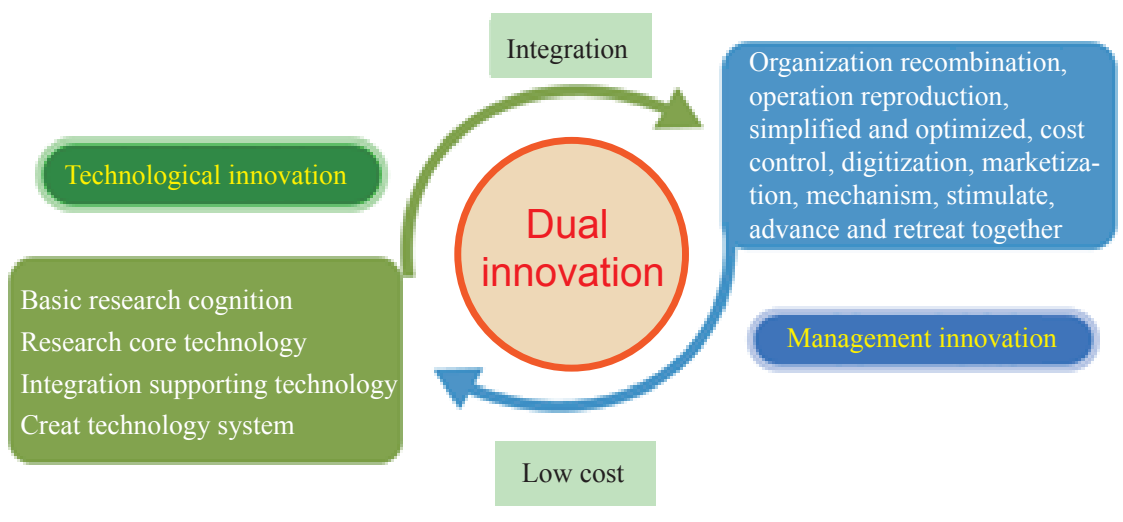

Figure 6. Schematic diagram of low cost dual integrations innovation. 
od was applied in the technology research of the Sulige tight gas field development, which putted the search of development technology route and two core technology development and management system as the key research contents, the four key development technology and organization system and management model as the second key point, the six supporting technology and the allocation of production factors, daily management, external coordination and culture publicity as the general content. And then the field implemented them according to the rigid contents, sub contents, attribute contents and flexible content gradually. After 7 years of research and development, the Sulige tight gas field realized large-scale development in 2008 and has become the highest domestic gas fields.

\subsubsection{The theory of development economic limit}

The so-called economic limits means at each stage of oil and gas field development and capital investment, setting maximum or stable output of oil and gas fields as the criterion after production to calculate the corresponding investment returns and investment profits. If the output has economic benefit, then start the development project, otherwise, give up development temporarily. Firstly, setting the development economic limits should fully recognize the significance of enterprise benefits and social benefits by developing such types of oil and gas fields; secondly, the most basic target parameter should be set on the conditions of complete research and discussion; thirdly, it should fully consider the contribution value of technical progress; Fourthly, it is better to address the role of radiation and promotion of developing similar oil and gas fields (Hu \& Zhai, 2010). Under the guidance of economic limit theory, Petro China invested 3 billion Yuan (appropriately floating) to construct one hundred million cubic meter productivity of coal-bed methane, while ensuring the economic benefit.

\subsubsection{Integrated operation}

Integrated operation refers to combining several dispersed elements and essential factors into one platform with modern techniques, so as to achieve the effective control, rapid reaction, and time saving decision-making purposes. The greatest advantage of it is eliminating the barriers in the organization and artificial dissection, so that the working conditions can be monitored and controlled timely and accurately and anyone can view real-time data and adjust their work status at any place to meet the process requirement (Hu, 2009B). Since the beginning of 2001, according to the problems encountered in the development of the Sulige tight gas field, 13 domestic and foreign research institutions and companies has been organized together to integrate the technology resources and carried out 7 years of research to establish and improve the multidisciplinary integrated research system (see Figure7). The essence of the Sulige Gas Field integrated research system is to integrate China National Petroleum Corporation and other famous international oil companies to collaboratively innovate on a large scale.

\subsubsection{The "four modernizations" development philosophy}

"Four modernizations" refers to "standardized design, modular construction, digital management and market operation". It is a basic route made after successful pilot development of Sulige Gas Field, and then is applied to develop and construct of the Sulige Gas Field on a large scale, which is organic combination of technology innovation and management innovation $(\mathrm{Hu}, 2008)$. Standard design refers to design a set of general, standard, relative stable and suitable for guiding ground construction and operational file to unify gas field construction specification. It mainly contains unified process, unified layout, unified construction standards, unified module setting, unified equipment selection, and unified piping design. The standardized design coverage rate reached to of $100 \%$ after implementation in Sulige Gas Field and, and the gas field surface engineering design period is shortened by $60 \%$ with improved design quality. Modular construction refers to classify each technical aspects of the gas station and determine the design of the dif-

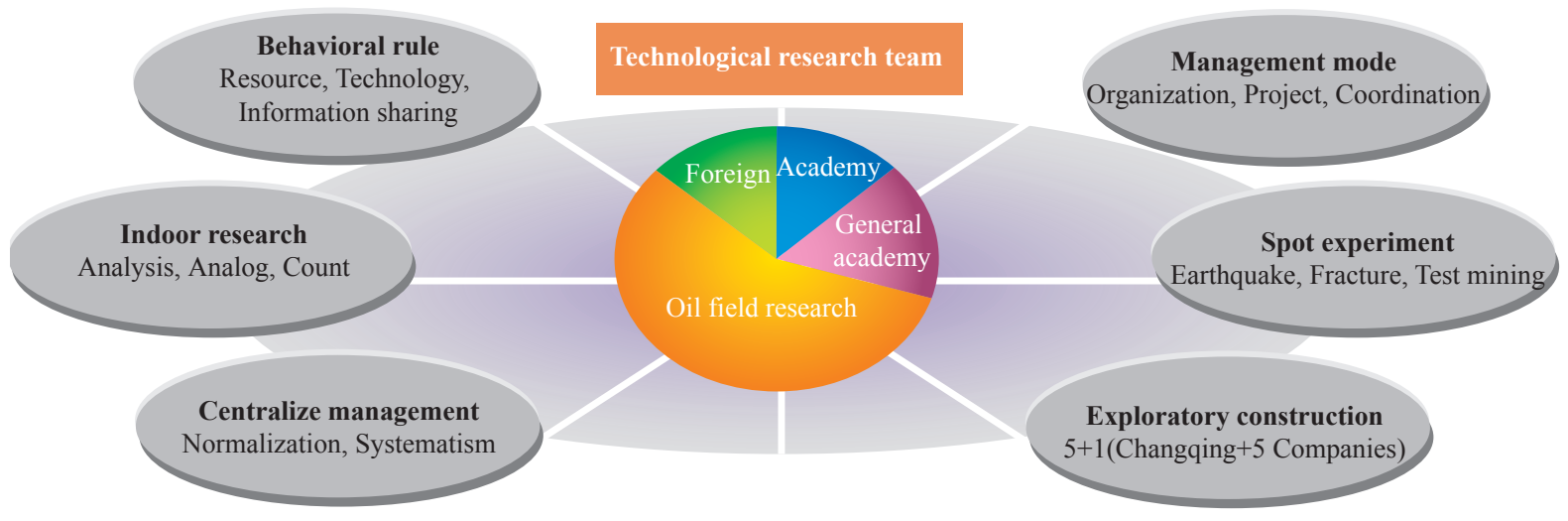

Figure 7. Schematic diagram of the integrated operation of the Sulige gas field. 
ferent single equipment and the different scale of processing module, and then the prefabricated components were modular produced in factory under process flow with programmable process control in large scale and then installed as plug-in pattern and manage the construction in digital. It realizes all-weather operation and the gas gathering station construction period is shortened from 110 days to 30 days, treatment plant construction period is shortened from 14 months to 9 months.

Digital management refers to the use of computer, communication, and network, intelligent control technology to set single well station, pipeline, and basic unit as the key points. The basic production unit process controlling is the front end core, the basic gathering unit operation management as is the middle core and the gas reservoir management decision system with the integration of collaborative work platform is the back end core. It realizes intelligent managing gas well, early warning the production and operation system's risk, remote controlling and gas reservoir real-time monitoring, dynamic optimizing, timely adjustment (Lu, 2013) (see Figure 8). It streamlines the organization, reduces the labor intensity, the number of workers, and greatly reduces the operation cost. Market operation refers to marketization of project services and implementation of a unified price system in the development of the Sulige Gas Field. By managing the construction team, applying unified engineering service standards and unified supervision, build a fair market with multi-party participation and free competition to ensure the project quality. After application and implementation of the development and construction concept of "four modernizations" in the Sulige Gas Field, the development costs are effectively controlled, single well drilling cost is reduced by $40 \%$, the ground construction investment is reduced by $50 \%$, greatly improved the field's development efficiency and effectiveness.
4.2 The construction of "two low" engineering management system

In the process of developing the Sulige tight gas field, a complete set of "two low" engineering management system was formed, covering the technology innovation and management innovation through the continuous innovation of technology and management according to the characteristics of tight gas field (see Figure 9).

The biggest advantage of this is changing the impossible produced low grade resource into recoverable resources in large scale development, and unifying the underground natural objects and artifacts on the ground, realizing the aim of increasing single well production and reducing development cost and exploring a route of effectively developing unconventional gas resources. This route is "the Sulige Curve", which is learning curve and practice curve (see Figure 10). The Sulige Gas Field development technology has experienced the three stages of the conventional technology, application of new technology and application of high-tech. Single well gas production gradually increased with improving technology level. In the process of developing the Sulige Gas Field, engineering management innovation has been promoted with emancipating the mind, such as put forward the low cost development route, " $5+1$ " cooperative development and management system, the "four modernizations" construction mode, which breaks through the limit of management mechanism, fully address the role of the market and greatly reduce the cost of development and construction.

The gas production of Sulige Gas Field has increased rapidly, and it became the highest production field in China in 2010 and annual production exceed more than $210 \times 10^{4}$ $\mathrm{m}^{3}$ in 2013 , which accounted for $17.4 \%$ of total Chinese natural gas output.

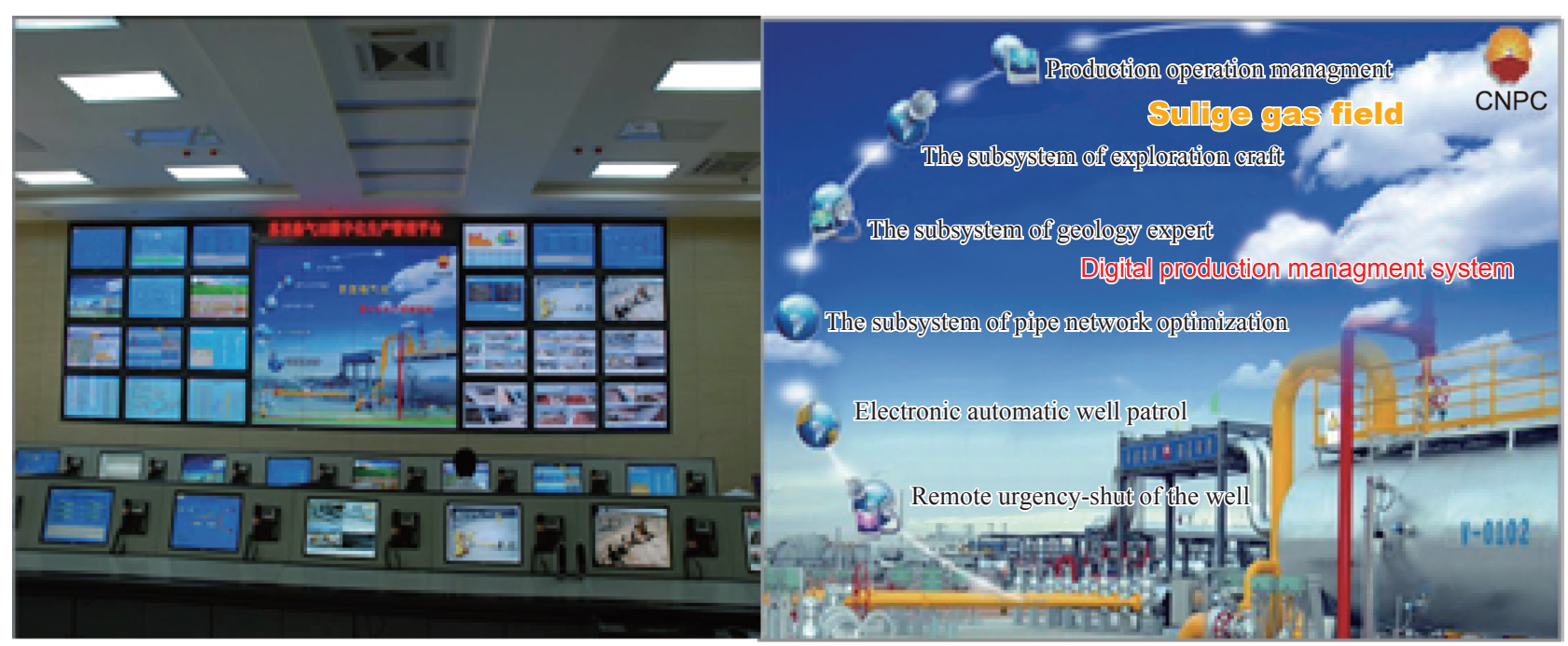

Figure 8. Digital production system in the Sulige gas field. 


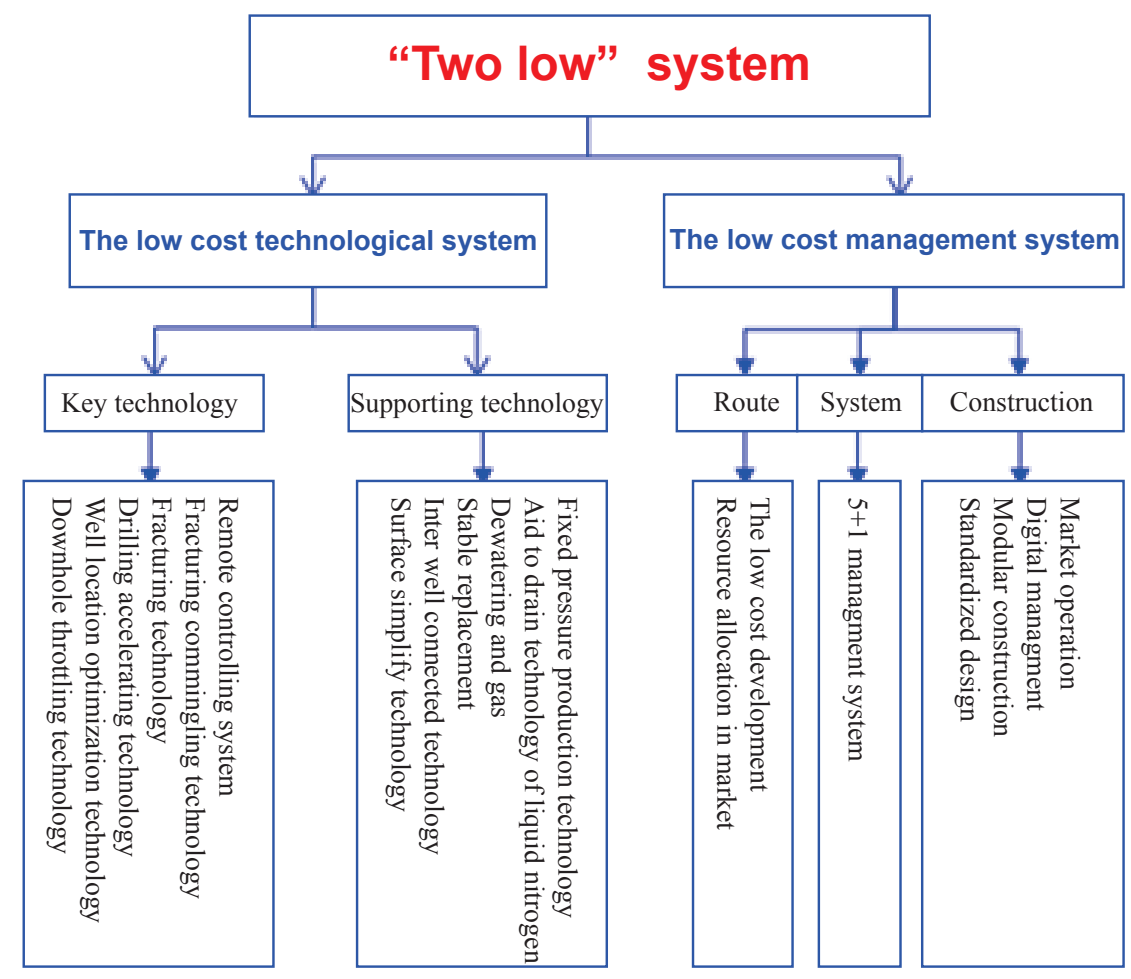

Figure 9. "Two low" engineering management system.

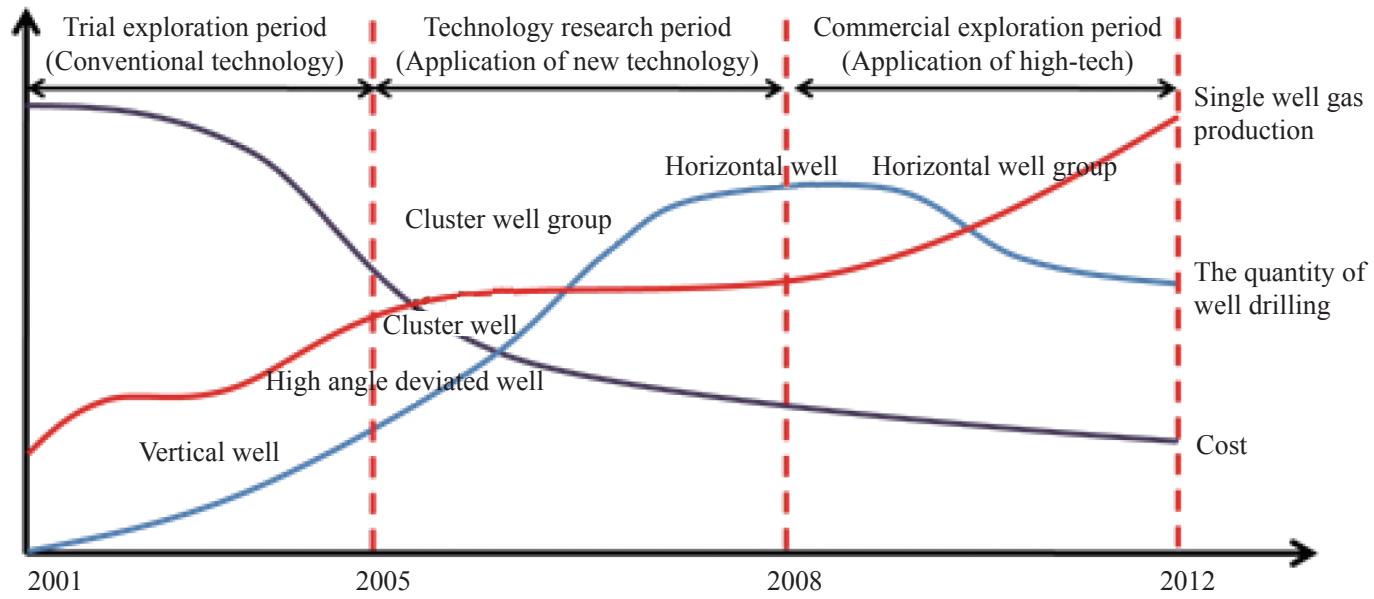

Figure 10. The development curve of Sulige gas field.

4.3 Creating special unconventional natural gas development mode

\subsubsection{Sulige tight gas development mode}

The Sulige tight gas field has been the largest gas field in China so far, and the proven reserves plus basic proven reserves reach 3.49 trillion cubic meters in 2013, but it is also a typical "three low" (low permeability, low pressure and low resource abundance) gas field with extreme development difficulty in the world at the same time. Since its discovery in 2001, after 7 years of research on technology and management innovation, the " $5+1$ " cooperative development mode and the "six unified, three sharing, one centralized" management mechanism were explored. The "standardized design, modular construction, digital management and market operation" was fully implemented to the whole field and the twelve matching development technology that suitable for 
Sulige's geological characteristics was integrated and innovated and formed the low pressure gas gathering process. The "Sulige Mode" was created and large scale economic development was realized.

Sulige tight gas development mode increase the single well production from $8,000 \mathrm{~m}^{3} / \mathrm{d}$ at the time of development pilots to $12,000 \mathrm{~m}^{3} / \mathrm{d}$ in 2008 , and reduce the single well drilling cost from $12,000,000$ yuan to $8,000,000$ yuan; the preconception that the owner develops his own mineral rights was broken, and the " $5+1$ " cooperative development mode was explored, and the resources was allocated by market, all of these increase the pace of developing and constructing the Sulige Gas Field; The "six unified, three sharing, one centralized" management mechanism solved the problems of different technical standards and broke the barriers in the coordination of production and management; The implementation of "standardized design, modular construction, digital management and market-oriented" not only ensure the project quality but also reduce the construction cost. The annual production is 21 billion cubic meters in 2013 and became the largest gas field in China, and the planned annual production in 2015 is 23 billion cubic meters.

The Sulige tight gas field is the first effective scale development field in China and the "Sulige Mode" explored a successful ways of developing tight gas field, which has significant meanings of guiding the development and construction of similar gas fields in China.

4.3.2 The development model of coal-bed methane in the Qinshui Basin

The Qinshui Basin is one of the most coal-bed methane rich basins, and also the earliest developed CBM field in China. Since the large scale development and construction in 2005, a variety of cooperation exploitation mode including Jincheng, Luan, Liangou and Yamei has been formed with the persisting of exploiting coal-bed methane before coal mining and integrating coal mining and gas extraction policy. That helped resolving equity issues and realizing complementary advantages. Staff has formed five high rank coal exploration technology, established a coal-bed methane 'three low' gas collection process, which is measurement at wellhead, multistage concatenating, gas and water separating transferring, pressurizing on demand, and centralized treatment. Industry, university and research institutions cooperated to tackle key problems, found the CBM industry technology innovation strategic alliance. A brand new industrial development pattern, which is technology industrialization, construction standardization, work field automation, operation marketization, upstream and downstream integration, and organization flattening, was presented and practiced. This reduced the single well investment and construction period by $30 \%$, promoted rapid progress of coal-bed methane industry. By the end of 2012, the Qinshui Basin has obtained 2.3 billion cubic meter of coal-bed methane, built the first large-scale and digital production base, which is the largest one in China at present.

\section{The challenges}

(1) Technical challenges. After years of research, the development of unconventional natural gas forms a large number of applicable technologies, but they are not mature enough in general (except for tight gas). The key technology suitable for Chinese unconventional reservoir characteristics are not yet fully formed, such as high-rank coal fracturing technology, shale gas horizontal well fracturing technology plus staged fracturing technology.

(2) Cost challenges. Unconventional gas development in China is of complex geological conditions, buried deep and mountainous surface, thus it is very difficult to develop under high cost and small scale (excluding tight gas). Technologies are often hold in the hands of a few companies, resulting in reducing costs is difficult; to lower development cost still require continuous technology and management research.

(3) Policy challenges. Unconventional gas is essentially a "lean ore" with poor economic benefit, which needs national policy supporting in the early development stages and that is the experience why United States' unconventional gas has been developed rapidly. In addition to the continuing introduce of incentives, the government needs to further decentralization, simplification approval, strengthen supervision, to allow the market to play a greater role in enhancing the initiative of strong company to enter the field of unconventional gas.

(4) Environmental challenges. Unconventional gas development often requires large amount of water, if the fracturing fluid with additives flow into freshwater aquifers, it will lead to an environmental crisis; if the discharged fluid come out from fracturing well and flow into rivers and lakes, it will also have some environmental impact.

\section{The recommendations on accelerating development of unconventional gas in China}

(1) Increasing support to the exploration and development of unconventional gas, such as adding tight gas, coal-bed methane and shale gas price subsidies, etc.; set the exploration and development of unconventional gas as single national major project to enforce technology research, while it is not suitable for adding to the existing special project of "development of large oil and gas fields and coal-bed methane".

(2) Accelerating the reform of natural gas prices, change the current status that natural gas prices are too low, and fundamentally improve the enterprises' initiative to participate in developing unconventional natural gas.

(3) Establishing national comprehensive utilization and demonstration area of unconventional gas. Developing of unconventional natural gas is technically difficult, involves many departments and there is no mature operation mecha- 
nism. It is better to establish a comprehensive utilization and demonstration area of developing unconventional gas from a national level, including technology demonstration, management model, industrialization demonstration, policy demonstration and administration demonstration to explore a set of management and operation mechanisms in accordance with our country's condition to promote the rapid development of the whole industry.

(4) Keeping sustainable technology research of unconventional natural gas development technologies. Organizing national level research platform to explore the key and common technologies that influence unconventional natural gas development through the introduction of absorption and re-innovation to form the core technology that adaptable with Chinese geological characteristics; For other supporting technologies, they can be gotten through moderate improvement on the basis of existing related technology of natural gas combining the characteristics of different types of natural gas.

(5) Paying attention to and continuing to promote the engineering management of developing unconventional natural gas. Development of low grade unconventional natural gas must take the low cost route, realization of low cost depends not only on technology innovation, but also rely on the management innovation and sometimes management innovation is much more difficult than technology innovation .Unconventional natural gas development must adhere to the principle of unconventional philosophy, unconventional organization, unconventional path, actively cultivate and optimize the "low cost technology plus low cost management" system, create and summarize the typical model of developing unconventional gas, to achieve the scale development of low grade resource and get good economic benefit.

\section{References}

Chen, Y., Yang, J., Wang, Y., Chen, Z., \& Wang, X. (2010). Optimization of casing program and its application to coal-bed methane pinnate horizontal well. Oil Drilling \& Production Technology,
32(4), $81-85$

$\mathrm{Hu}, \mathrm{W}$. (1991). Theory of full-range network management. Lanzhou: Gansu People's Press

$\mathrm{Hu}, \mathrm{W}$. (2008). Administration model innovation and technology innovation in development of the Sulige Gas Field. Science \& Technology Progress and Policy, 25(10), 112-115

$\mathrm{Hu}, \mathrm{W}$. (2009A). The present and future of low permeability oil and gas in China. Engineering Sciences, 11(8), 29-36

Hu, W. (2009B). Theory of Low-permeability reservoir. Beijing: Petroleum Industry Press

$\mathrm{Hu}, \mathrm{W}$. (2010). Development of unconventional natural gas: the best approach to low-carbon economy and resource efficiency. Natural Gas Industry, 30(9), 385-397

Hu, W. (2013A). Resources, status, problems and solutions of unconventional gas in China (pp. 7-10). Beijing: China National Petroleum Corporation (CNPC) Advisory Centre

$\mathrm{Hu}, \mathrm{W}$. (2013B). To explore the way of Chinese-style shale gas development. Natural Gas Industry, 33(1), 1-7

Hu, W., \& Zhai, G. (2010). Practice and sustainable development of oil and nature gas exploration and development in Ordos Basin. Engineering Sciences, 10(5), 64-72

Lu, T. (2013). Successful development practice of the Sulige Gas Field (pp.17-22). Shanxi: Xi'an Changqing Oilfield Company of Petro China

Qiu, Z., \& Deng, S. (2012). Strategic position of unconventional oil \& gas in China. Natural Gas Industry, 32(1), 1-5

Wu, Q. (2013). Key technology progress of tight oil \& gas (6-21). Beijing: E \& P Company of Petro China

Zhao, W. (2012). Resource potential and future development status of unconventional as in China (pp. 10-30). Beijing: Chinese Academy of Engineering

Zhou, X. (2013). Interim report of demonstration project of coal-bed methane horizontal well development in the Qinshui Basin in Shanxi (pp. 43-49). Jincheng: Huabei Oilfield Company of Petro China

Zou, C., Zhang, G., Yang, Z., Tao S., Hou L., Zhu R., Yuan X., Ran Q., Li D., Wang Z.(2013). Geological concepts, characteristics, resource potential and key techniques of unconventional hydrocarbon: on unconventional petroleum geology. Petroleum Exploration and Development, 40(4), 1-8 